\title{
A Primary Screening Method for Liver Cancer in Chronic Hepatitis B Carriers: A Prospective Community- Based Cohort Study
}

\author{
Maomao Cao ${ }^{1}, \mathrm{He} \mathrm{Li}{ }^{1}$, Dianqin Sun ${ }^{1}$, Siyi He ${ }^{1}$, Changfa Xia ${ }^{1}$, Lin $\mathrm{Lei}^{2}$, Ji Peng ${ }^{2}$ \\ and Wanqing Chen ${ }^{1 *}$
}

1 Office of Cancer Screening, National Cancer Center/National Clinical Research Center for Cancer/Cancer Hospital, Chinese Academy of Medical Sciences and Peking Union Medical College/Chinese Academy of Medical Sciences Key Laboratory for National Cancer Big Data Analysis and Implement, Beijing, China, ${ }^{2}$ Department of Cancer Prevention and Control, Shenzhen Center for Chronic Disease Control, Shenzhen, China

\section{OPEN ACCESS}

Edited by:

Teresita Padilla-Benavides, Wesleyan University, United States

Reviewed by:

Zhenqiu Liu,

Fudan University, China

Alma D. Campos-Parra,

National Institute of Cancerology

(INCAN), Mexico

*Correspondence:

Wanqing Chen

chenwq@cicams.ac.cn

Specialty section:

This article was submitted to Gastrointestinal Cancers: Hepato

Pancreatic Biliary Cancers,

a section of the journal

Frontiers in Oncology

Received: 24 August 2021 Accepted: 06 December 2021

Published: 03 January 2022

Citation:

Cao M, Li H, Sun D, He S, Xia C, Lei L, Peng J and Chen W (2022)

A Primary Screening Method

for Liver Cancer in Chronic

Hepatitis B Carriers: A Prospective Community-Based Cohort Study.

Front. Oncol. 11:762662.

doi: 10.3389/fonc.2021.762662
Background: Patients with hepatitis B virus (HBV) were invited to receive ultrasound and alpha-protein examination directly in China. However, not all HBV carriers need to be subjected to further tests. This study aimed to develop a feasible primary screening method to narrow down potential high-risk individuals of liver cancer among populations with HBV.

Methods: Based on a prospective community-based cohort, potential risk factors were selected as the predictors, including age, sex, smoking, alcohol consumption, diabetes, liver cancer family history, liver diseases in mothers, source of water, body mass index (BMI), and psychological trauma. Cox proportional regression model was applied to predict the 3-year absolute risk of liver cancer and derive risk scores. The area under receiver operating characteristic curve (AUROC) and calibration plot were used to assess the performance of the model. Bootstrap resampling was used for internal validation.

Results: Age, sex, BMI, alcohol consumption, liver diseases in mothers, and psychological trauma were independent risks of liver cancer. The 1- to 3-year AUROC of the prediction model was $71.15 \%(95 \% \mathrm{Cl}, 66.88-75.42), 71.16 \%(95 \% \mathrm{Cl}, 67.42-$ 74.90), and $72.95 \%(95 \% \mathrm{Cl}, 64.20-81.70)$, respectively. The predicted risk was calibrated well with the observed liver cancer risk. Bootstrap resampling showed that C-index was 0.70 (0.67-0.74). A 32-point risk score was also developed and a score over 5 was identified for patients at extremely high risk.

Conclusions: A user-friendly primary screening method was created that could estimate the 3-year absolute risk of liver cancer and identify extremely high-risk individuals among the population with HBV.

Keywords: primary liver cancer screening, high-risk population, incidence risk, prediction model, epidemiological risk factors 


\section{INTRODUCTION}

In 2016, World Health Organization (WHO) set an ambitious goal of viral hepatitis elimination by 2030 , and reducing the hepatitis B virus (HBV)- and hepatitis $\mathrm{C}$ virus (HCV)-associated mortality by $65 \%$ (1). As an important cause of HBV-related mortality in China and worldwide, liver cancer represented $21 \%$ of mortality globally (2). Thus, to meet the WHO targets, the importance is to reduce the liver cancer burden. Liver cancer screening offers substantial potential to detect cases at an early stage and prolong their survival rate (3-5). In China, liver cancer screening has been covered by three National Key Public Health Services, which provide free screening services aiming at highrisk population or individuals from high-risk regions (6).

Fifty percent to $80 \%$ of primary liver cancer cases result from $\mathrm{HBV}$ chronic infection (7); thus, hepatitis B surface antigen ( $\mathrm{HBsAg}$ ) test is an essential and crucial method at the primary stage of liver cancer screening to identify high-risk individuals. According to the Technological Program on Cancer Early Detection and Treatment in 2011 in China (8), patients with HBV chronic infection were invited to receive ultrasound and alpha-fetoprotein (AFP) examinations directly. Although seropositive for HBsAg could increase the risk of liver cancer, only $6.2 \%-9.5 \%$ of HBV carriers eventually develop liver cancer if without the occurrence of cirrhosis (9). A risk prediction model for liver cancer based on age, sex, HBeAg, and HBV DNA levels also showed that low-risk HBVinfected individuals had similar cumulative probabilities of developing liver cancer compared with the HBsAg-negative participants, suggesting that $\mathrm{HBV}$ carriers at low risk may not need the same surveillance scheme as the high-risk HBV carriers (10). The evidence mentioned above suggests that it may be inappropriate for all patients with HBV chronic infection to be screened. For these reasons, identifying extremely high-risk individuals and optimizing the method of primary screening are necessary among patients chronically infected with HBV for liver cancer screening.

Available prediction models for liver cancer generally included serum biomarkers (e.g., white cell count) in a combination with epidemiological information (11-13). However, these models are relatively complex and not easy to use to identify the potential highrisk individuals at the primary stage of liver cancer screening among HBV carriers. In this study, we aimed to develop a noninvasive risk assessment tool to calculate individualized risk and identify extremely high-risk individuals of liver cancer among populations with HBV chronic infection based on traditional epidemiological risk factors of liver cancer only.

\section{MATERIALS AND METHODS}

\section{Study Design and Participants}

The community-based cohort study on population with high risk of liver cancer (the CCOP-LC cohort) was initiated in 2017

Abbreviations: WHO, World Health Organization; HBV, Hepatitis B virus; HCV, Hepatitis C virus; HBsAg, Hepatitis B surface antigen; AFP, Alpha-fetoprotein; BMI, Body mass index; HR, Hazard ratio; CI, Confidence interval; AUROC, Area under receiver operating characteristic curve; $\mathrm{CHB}$, Chronic hepatitis $\mathrm{B}$. among residents aged 35-70 years in seven sites (Binhai county, Lingbi county, Mengcheng county, Sheyang county, Shenqiu county, Dancheng county, and Yingdong county), which has been described previously (14). All participants had to take immunochromatographic strip tests for the detection of HBsAg; only the HBsAg-positive patients were enrolled in the final cohort. Patients who received antiviral treatment or were diagnosed with liver cancer or other malignant diseases at initial enrollment were excluded.

The epidemiological research has been registered in Chinese Clinical Trial Registry (identifier: ChiCTR-EOC-17012853). This study was approved by the Ethics Review Committee of the Cancer Hospital, Chinese Academy and Medical Sciences. Written informed consent was obtained from all participants.

\section{Liver Cancer Ascertainment and Follow-Up}

At baseline, patients who received liver cancer screening and showed suspicious or positive results were invited to CT/MRI to confirm the diagnosis. A mixed follow-up method was applied at the follow-up stage. An active follow-up approach was conducted initially, and then we linked all cohort populations with the local Cancer Registration database and Death Surveillance database to obtain information on cancer incidence and all-cause mortality, and then cross-referred them to medical insurance databases or medical records from local hospitals. All participants were followed up until December 31, 2020.

\section{Risk Factors Measurement}

A standardized self-administered epidemiological questionnaire was offered to each participant by face-to-face interview to collect demographic characteristics, lifestyle, and medical history. Potential risk factors were selected as the predictors, including age, sex, smoking, alcohol consumption, diabetes, family history of liver cancer, liver diseases in mothers, source of water, body mass index (BMI), and psychological trauma. Candidate risk factors identified for inclusion in this study were those previously shown significantly associated with the development of liver cancer $(15,16)$. Participants were asked for information on the frequency of alcohol consumption, average alcohol consumption per week, and types of drinks. Ethanol content differed for each type of alcohol and was assumed to be the same measurement method as follows: $180 \mathrm{ml}$ sake (rice wine) as $23 \mathrm{~g}$ ethanol, 180 $\mathrm{ml}$ white spirits as $36 \mathrm{~g}, 633 \mathrm{ml}$ beer as $23 \mathrm{~g}$, and $60 \mathrm{ml}$ wine as $6 \mathrm{~g}$ (17). Weekly alcohol consumption levels were classified into three groups (never, $0-550 \mathrm{~g} / \mathrm{ethanol}, \geq 550 \mathrm{~g} / \mathrm{ethanol}$ ). The question on smoking habits includes current and former smoking status, age at initiation of smoking, average number of cigarettes per day, and types of smoking [ 1 cigarette $=1 \mathrm{~g}$ of tobacco $=0.5$ cigars (18)]. The smoking intensity was evaluated by pack-year defined by multiplying the number of years of smoking by the average number of cigarettes per day divided by 20 (19). We classified smokers by the following categories of smoking intensity: never, light ( $<20$ pack-years for females, $<30$ pack-years for males), and heavy ( $\geq 20$ pack-years for females and $\geq 30$ for males). BMI was calculated as weight in kilograms 
divided by height in meters squared and classified into $<25 \mathrm{~kg} / \mathrm{m}^{2}$ and $\geq 25 \mathrm{~kg} / \mathrm{m}^{2}$ according to the criteria in the diagnosis of obesity from WHO for Asian and South Asian population (20). History of diabetes was collected through self-report. Perinatal transmission (from mother to infant at birth) is the most common route for the transmission of hepatitis B virus in China, and thus maternal liver disease is an important risk factor for liver cancer. In this study, maternal liver diseases referred to liver diseases in mothers, including liver cancer, chronic hepatitis $\mathrm{B}$, and other liver diseases, which were detected among 1,553 persons, of them, 641 (41.27\%) mothers were diagnosed with chronic hepatitis B and 482 (31.04\%) mothers had liver cancer.

\section{Statistical Analysis}

Continuous variables were expressed as means \pm standard deviations, whereas categorical variables were presented as numbers and percentages. Person-years at risk were counted from enrollment until liver cancer diagnosis, death, or December 31, 2020, whichever occurred first. Pearson's Chi-square or Fisher exact tests were performed to compare the categorical variables. Cox proportional regression model with the backward method was applied to screen possible independent risk factors and acquire hazard ratios (HRs) and corresponding 95\% confidence intervals (CIs). Proportional hazard assumptions were assessed by martingale residual. The time-dependent area under receiver operating characteristic curve (AUROC) and calibration plot were used to assess the discriminatory ability and goodness of fit. A total of 1,000 bootstrap samples were used for internal validation, presenting as concordance index (C-index).

The 3-year absolute risks of liver cancer were calculated using the following standard equation $(21,22)$ :

$$
F(t)=1-S(t)^{\exp \left(f\left[x, \mathrm{M}_{i}\right]\right)} ; f\left[x, M_{i}\right]=\sum_{i=1}^{P} \beta_{i} X_{i} \sum_{i=1}^{P} \beta_{i} \bar{x}_{i}
$$

where $F(t)$ refers to the probability of developing liver cancer in $t$ years; $S(t)$ is the baseline disease-free probability; $P$ is the number of the statistical variables; $\beta_{i}$ is the regression coefficient for the $i$ th variables; and $\bar{x}_{i}$ is the mean level of $i$ th covariates.

A simple-to-use risk score was derived based on the following six steps (21):

1. Selecting independent risk factors and corresponding coefficients obtained from the Cox proportional hazards regression model;

2. Calculating means (or proportions) for each risk-factor category of the risk factors and baseline disease-free probability;

3. Determining a reference value for each category of each risk factor and choosing a base category for each risk factor;

4. Computing weighted distance between each category of each risk factor and base category using $\beta_{\mathrm{i}} \times\left(\mathrm{W}_{\mathrm{ij}}-\mathrm{W}_{\mathrm{iREF}}\right)$;

5. Setting the constant $\mathrm{B}$, and in this study, $\mathrm{B}=5^{\star} \beta_{\text {age; }}$; and

6. Integer risk score $=\left[\beta_{\mathrm{i}} \times\left(\mathrm{W}_{\mathrm{ij}}-\mathrm{W}_{\mathrm{iREF}}\right)\right] / \mathrm{B}$.

To ease the application of the risk score, cutoff values were determined by the Youden index, sensitivity, specificity, and the purpose of the study comprehensively. The 3-year cumulative risk of liver cancer was calculated using the Kaplan-Meier method and compared with the log-rank rest. All statistical tests were two-sided and a $p$ of $<0.05$ was considered statistically significant. Missing data were excluded directly. Analyses were conducted by using SAS version 9.4 (SAS Institute, Cary, NC, USA) and R version 4.0.4.

\section{RESULTS}

\section{Baseline Characteristics of the Participants}

A total of 10,536 patients were included in the present study. At a median follow-up period of 2.64 years, 203 patients developed liver cancer (1.93\%). Table 1 shows the baseline demographic characteristics and liver cancer potential risk factors. Patients diagnosed with liver cancer were more likely to be older $(p<$ $0.001)$. The number of liver cancer cases in males was significantly higher than that in females, accounting for $66.01 \%$ and $33.99 \%$ of all cases, respectively $(p<0.001)$. BMI, smoking, alcohol consumption, psychological trauma, and liver diseases in mothers also distributed statistically significantly different among patients with liver cancer and without liver cancer $(p<0.05)$.

\section{Predictors of the Development of Liver Cancer}

The results of univariate and multivariate analysis are summarized in Table 2 . In the univariate analysis, age (year; $\mathrm{HR}=1.05,95 \% \mathrm{CI}=1.04-1.07$ ), sex (male; $\mathrm{HR}=2.17$, $95 \% \mathrm{CI}=1.62-2.90), \mathrm{BMI}(<25 ; \mathrm{HR}=1.59,95 \% \mathrm{CI}=1.20-2.12)$, smoking (light; $\mathrm{HR}=1.76,95 \% \mathrm{CI}=1.26-2.46$; heavy; $\mathrm{HR}=$ $1.68,95 \% \mathrm{CI}=1.16-2.45)$, alcohol consumption $(\geq 550 \mathrm{~g} / \mathrm{week}$ ethanol; $\mathrm{HR}=2.85,95 \% \mathrm{CI}=1.40-5.81)$, liver diseases in mothers (yes, $\mathrm{HR}=1.47,95 \% \mathrm{CI}=1.05-2.07$ ), and psychological trauma (yes; $\mathrm{HR}=1.53 ; 95 \% \mathrm{CI}=1.14-2.05$ ) were associated with the development of liver cancer. By multivariate comparison, except for smoking, the following 5 variables were still independently related to the presence of liver cancer: age in years $(\mathrm{HR}=1.06,95 \% \mathrm{CI}=1.04-1.08)$, male gender $(\mathrm{HR}=2.41,95 \% \mathrm{CI}=1.76-3.29), \mathrm{BMI}<25(\mathrm{HR}=1.46$, $95 \% \mathrm{CI}=1.10-1.95)$, alcohol consumption $\geq 550 \mathrm{~g} /$ week ethanol $(\mathrm{HR}=2.12,95 \% \mathrm{CI}=1.03-4.38)$, liver diseases in mothers $(\mathrm{HR}=$ $1.84,95 \% \mathrm{CI}=1.30-2.61$ ), and presence of psychological trauma $(\mathrm{HR}=1.62,95 \% \mathrm{CI}=1.20-2.18)$.

\section{Development of the Risk Prediction Model and Derivation of the Risk Score for Liver Cancer}

The statistically significant variables were selected to construct the risk prediction model, which was presented as follows: $F(t)=1-S(t)^{\exp (f, M)} ; \mathrm{f}, \mathrm{M}=\sum_{i=1}^{p} \beta_{i} X_{i}-\sum_{i=1}^{p} \beta_{i} \bar{x}_{i}=0.058 \times$ (age in years) $+0.879 \times($ Female $=0$, Male $=1)+0.608 \times($ liver diseases in mother: Yes $=1$, No $=0)+0.380 \times\left(\mathrm{BMI}_{<25}=1\right.$, $\left.\mathrm{BMI}_{\geq 25}=0\right)+0.753 \times($ alcohol consumption $\geq 550 \mathrm{~g} /$ week ethanol: 
TABLE 1 | Baseline characteristics of the study patients with chronic HBV.

\begin{tabular}{|c|c|c|c|c|}
\hline \multirow[t]{2}{*}{ Variables } & \multirow[t]{2}{*}{ All $(N=10,536)$} & \multicolumn{2}{|c|}{ Liver cancer development (\%) } & \multirow[t]{2}{*}{$\mathbf{p}$} \\
\hline & & No $(N=10,333)$ & Yes $(N=203)$ & \\
\hline Age, years & & & & $<.001$ \\
\hline 35-39 & $550(5.22)$ & $547(5.29)$ & $3(1.48)$ & \\
\hline $40-44$ & $840(7.97)$ & $830(8.03)$ & $10(4.93)$ & \\
\hline $45-49$ & $1,615(15.33)$ & $1,590(15.39)$ & 25 (12.32) & \\
\hline $50-54$ & $2,059(19.54)$ & $2,036(19.70)$ & $23(11.33)$ & \\
\hline $55-59$ & $1,627(15.44)$ & $1,600(15.48)$ & 27 (13.30) & \\
\hline $60-64$ & $1,874(17.79)$ & $1,830(17.71)$ & $44(21.67)$ & \\
\hline 65-70 & $1,971(18.71)$ & 1,900 (18.39) & $71(34.98)$ & \\
\hline Sex & & & & $<.001$ \\
\hline Male & $4,991(47.37)$ & $4,857(47.00)$ & $134(66.01)$ & \\
\hline Female & $5,545(52.63)$ & $5,476(53.00)$ & 69 (33.99) & \\
\hline Marriage & & & & 0.012 \\
\hline Unmarried & $167(1.59)$ & $158(1.53)$ & $9(4.43)$ & \\
\hline Married & 9,649 (91.58) & 9,468 (91.63) & $181(89.16)$ & \\
\hline Divorced & $75(0.71)$ & $74(0.72)$ & $1(0.49)$ & \\
\hline Widow & $645(6.12)$ & $633(6.13)$ & $12(5.91)$ & \\
\hline Educational level & & & & 0.486 \\
\hline No schooling & $3,462(32.86)$ & $3,388(32.79)$ & $74(36.45)$ & \\
\hline Primary school & $3,194(30.32)$ & $3,142(30.41)$ & $52(25.62)$ & \\
\hline Middle school & $3,034(28.8)$ & $2,973(28.77)$ & $61(30.05)$ & \\
\hline Junior college above & $846(8.03)$ & 830 (8.03) & $16(7.88)$ & \\
\hline Water source & & & & 0.283 \\
\hline Cellar water, pond water and shallow well water, Lakes and rivers & $2,020(19.17)$ & $1,973(19.09)$ & $47(23.15)$ & \\
\hline Deep well water and springs & $2,049(19.45)$ & $2,008(19.43)$ & $41(20.20)$ & \\
\hline Tap water & $6,467(61.38)$ & $6,352(61.47)$ & $115(56.65)$ & \\
\hline $\mathrm{BMI}\left(\mathrm{kg} / \mathrm{m}^{2}\right)$ & & & & 0.001 \\
\hline$<25$ & $5,461(51.83)$ & $5,333(51.61)$ & $128(63.05)$ & \\
\hline$\geq 25$ & $5,075(48.17)$ & $5,000(48.39)$ & $75(36.95)$ & \\
\hline Smoking & & & & 0.001 \\
\hline Never & $7,424(70.46)$ & $7,306(70.71)$ & $118(58.13)$ & \\
\hline Light & $1,767(16.77)$ & $1,718(16.63)$ & $49(24.14)$ & \\
\hline Heavy & $1,345(12.77)$ & $1,309(12.67)$ & $36(17.73)$ & \\
\hline Alcohol consumption (g/week ethanol) & & & & 0.010 \\
\hline No & $8,436(80.07)$ & $8,276(80.09)$ & $160(78.82)$ & \\
\hline$<550$ & $1,949(18.50)$ & $1,914(18.52)$ & $35(17.24)$ & \\
\hline$\geq 550$ & $151(1.43)$ & $143(1.38)$ & 8 (3.94) & \\
\hline Psychological trauma & & & & 0.005 \\
\hline No & $8,080(76.69)$ & $7941(76.85)$ & $139(68.47)$ & \\
\hline Yes & $2,456(23.31)$ & 2,392 (23.15) & $64(31.53)$ & \\
\hline Liver diseases in mothers & & & & 0.027 \\
\hline No & 8,983 (85.26) & $8,821(85.37)$ & $162(79.80)$ & \\
\hline Yes & $1,553(14.74)$ & $1,512(14.63)$ & $41(20.20)$ & \\
\hline Liver cancer family history & & & & 0.701 \\
\hline No & $8,874(84.23)$ & $8,705(84.24)$ & $169(83.25)$ & \\
\hline Yes & $1,662(15.77)$ & $1,628(15.76)$ & $34(16.75)$ & \\
\hline Diabetes & & & & 0.416 \\
\hline No & 9,805 (93.06) & 9,619 (93.09) & 186 (91.63) & \\
\hline Yes & 731 (6.94) & 714 (6.91) & 17 (8.37) & \\
\hline
\end{tabular}

Yes $=1$, No $=0)+0.480 \times($ psychological trauma: Yes $=1$, No $=$ 0) - 4.010. A detailed process to develop the risk prediction model is shown in Figure 1. Individual risk of developing liver cancer can be estimated by using this calculator.

A simple-to-use risk score was derived based on the risk prediction model, ranging from 0 to 32 (Table 3), which also could be used to estimate the risk of developing liver cancer roughly. For example, a male patient (risk score $=3$ ), aged 40 years (risk score $=1$ ), with a BMI of 30 (risk score $=0$ ), without psychological trauma (risk score $=0$ ), whose mother was not diagnosed with liver diseases (risk score $=0$ ), with alcohol consumption of $600 \mathrm{~g} /$ week ethanol (risk score $=3$ ) would have a cumulative risk score of 7 , and the 3-year projected liver cancer risk was $1.888 \%$ (Table 4). Cumulative risk of developing liver cancer of risk score at 1 year, 2 years, and 3 years for each score is also shown in Figure 2.

According to the assessment indices, the optimal cutoff value of the risk score was set at 5 with a sensitivity of $93.10 \%$, and $76.02 \%$ of patients were considered extremely high risk. By applying the cutoff point of 5 for the risk score, 2,527 patients and 8,009 patients were divided into low-risk and extreme-highrisk groups, respectively (Table 5). The cumulative risk of liver 
TABLE 2 | Variables associated with liver cancer development in Cox's model.

\begin{tabular}{|c|c|c|c|c|c|}
\hline Variables & Pearson-years & Cases & Crude HR(95\% Cl) & $\beta$ coefficient & Adjusted HR $(95 \% \mathrm{Cl})^{\mathrm{a}}$ \\
\hline Age, years & $26,769.33$ & 203 & $1.05(1.04-1.07)$ & 0.058 & $1.06(1.04-1.08)$ \\
\hline \multicolumn{6}{|l|}{ Sex } \\
\hline Female & $12,614.39$ & 69 & ref & & ref \\
\hline Male & $14,154.94$ & 134 & $2.17(1.62-2.90)$ & 0.879 & $2.41(1.76-3.29)$ \\
\hline \multicolumn{6}{|l|}{$\mathrm{BMI}\left(\mathrm{kg} / \mathrm{m}^{2}\right)$} \\
\hline$\geq 25$ & $12,913.46$ & 75 & ref & & ref \\
\hline$<25$ & $13,855.86$ & 128 & $1.59(1.20-2.12)$ & 0.38 & $1.46(1.10-1.95)$ \\
\hline \multicolumn{6}{|l|}{ Smoking } \\
\hline Never & $18,900.00$ & 118 & ref & & \\
\hline Light & $44,34.90$ & 49 & $1.76(1.26-2.46)$ & & \\
\hline Heavy & $34,34.42$ & 36 & $1.68(1.16-2.45)$ & & \\
\hline \multicolumn{6}{|l|}{ Alcohol consumption (g/week ethanol) } \\
\hline No & $21,442.92$ & 160 & ref & & ref \\
\hline$<550$ & $4,952.74$ & 35 & $0.95(0.66-1.37)$ & -0.368 & $0.69(0.47-1.02)$ \\
\hline$\geq 550$ & 373.66 & 8 & $2.85(1.40-5.81)$ & 0.753 & $2.12(1.03-4.38)$ \\
\hline \multicolumn{6}{|l|}{ Liver diseases in mothers } \\
\hline No & $22,859.53$ & 162 & ref & & ref \\
\hline Yes & $3,909.79$ & 41 & $1.47(1.05-2.07)$ & 0.608 & $1.84(1.30-2.61)$ \\
\hline \multicolumn{6}{|l|}{ Liver cancer family history } \\
\hline No & $22,537.16$ & 169 & ref & & \\
\hline Yes & $4,232.16$ & 34 & $1.07(0.74-1.55)$ & & \\
\hline \multicolumn{6}{|l|}{ Diabetes } \\
\hline No & $24,923.28$ & 186 & ref & & \\
\hline Yes & $18,46.05$ & 17 & $0.81(0.49-1.33)$ & & \\
\hline \multicolumn{6}{|l|}{ Water source } \\
\hline Cellar water, pond water and shallow well water, Lakes and rivers & $5,029.67$ & 47 & $1.33(0.95-1.87)$ & & \\
\hline Deep well water and springs & $4,985.55$ & 41 & $1.15(0.81-1.65)$ & & \\
\hline Tap water & $16,754.11$ & 115 & ref & & \\
\hline \multicolumn{6}{|l|}{ Psychological trauma } \\
\hline No & $20,582.11$ & 139 & ref & & ref \\
\hline Yes & $6,187.21$ & 64 & $1.53(1.14-2.05)$ & 0.48 & $1.62(1.20-2.18)$ \\
\hline
\end{tabular}

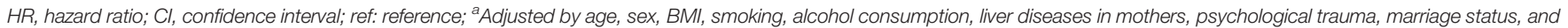
educational level.

cancer in the extreme-high-risk group was significantly higher than that in the low-risk group $(p<0.05$, Figure 3$)$.

\section{Performance of the Liver Risk Prediction Model}

The risk prediction model presented a satisfactory discrimination with AUROC of $71.15 \%$ (95\% CI $=66.88-$
75.42), $71.16 \%(95 \% \mathrm{CI}=67.42-74.90)$, and $72.95 \%$ (95\% CI $=$ $64.20-81.70)$ at 1 year, 2 years, and 3 years, respectively. The interval validation showed that the $\mathrm{C}$-index was $0.70(95 \% \mathrm{CI}=$ 0.67-0.74) (Figure 4). Calibration curves were generated for 1 year and 3 years to evaluate the calibration of the prediction model, suggesting an excellent agreement between the observed risk and predicted probability of liver cancer (Figure 5).

$$
\begin{aligned}
& \mathrm{F}(\mathrm{t})=1-\mathrm{S}(\mathrm{t})^{\exp (f, M)} ; f, M=\sum_{i=1}^{P} \beta_{i} X_{i}-\sum_{i=1}^{P} \beta_{i} \bar{x}_{i} . \\
& \sum_{\mathrm{i}=1}^{\mathrm{P}} \beta_{\mathrm{i}} \mathrm{X}_{\mathrm{i}}=0.058 \times(\text { age in years })+0.879 \times(\text { sex })+0.608 *(\text { liver diseases in mothers })+0.380 \times\left(\mathrm{BMI}_{25}\right) \\
& +0.753 \times(\text { alcohol consumption } \geq 550 \mathrm{~g} / \text { week ethanol })+0.480 \times(\text { psychological trauma }) ; \\
& \sum_{\mathrm{i}=1}^{\mathrm{P}} \beta_{\mathrm{i}} \overline{\mathrm{x}}_{\mathrm{i}}=0.058 \times(55)+0.879 \times(0.47)+0.380 \times(0.52)+0.753 \times(0.01)+0.608 \times(0.15)+0.480 \times \\
& (0.23)=4.010 ; \\
& \mathrm{S}(1 \text {-year })=0.987 ; \mathrm{S}(2 \text {-year })=0.982 ; \mathrm{S}(3 \text {-year })=0.980 ; \\
& \mathrm{F}(\mathrm{t})=1-\mathrm{S}(\mathrm{t})^{\exp (f, M)} ; f, M=\sum_{i=1}^{P} \beta_{i} X_{i}-\sum_{i=1}^{P} \beta_{i} \bar{x}_{i}=0.058 \times(\text { age in years })+0.879 \times(\text { female }=0, \text { male }=1) \\
& +0.608 \times\left(\text { liver diseases in mothers: } \mathrm{Yes}=1, \mathrm{No}_{0}=0\right)+0.380 \times\left(\mathrm{BMI}_{25}=1, \mathrm{BMI}_{\geq 25}=0\right)+0.753 \times(\text { alcohol } \\
& \text { consumption } \geq 550 \mathrm{~g} / \text { week ethanol: } \mathrm{Yes}=1, \mathrm{No}=0)+0.480 \times(\text { psychological trauma: } \mathrm{Yes}=1, \mathrm{No}=0)-4.010
\end{aligned}
$$

FIGURE 1 | The process and final formula of liver cancer risk prediction model in hepatitis B patients. 
TABLE 3 | Components of risk score.

\begin{tabular}{lcc}
\hline Variables & Category & Risk score \\
\hline Sex & Female & 0 \\
Age & Male & 3 \\
& $35-39$ & 0 \\
& $40-44$ & 1 \\
& $45-49$ & 2 \\
& $50-54$ & 3 \\
BMl & $55-59$ & 4 \\
& $60-64$ & 5 \\
Alcohol consumption (g/week ethanol) & $65-70$ & 6 \\
& $\geq 25$ & 0 \\
& $<25$ & 1 \\
Liver diseases in mothers & No & 0 \\
Psychological trauma & $<550$ & 0 \\
& $\geq 550$ & 3 \\
\end{tabular}

\section{DISCUSSION}

This study developed and internally validated a risk prediction model and corresponding 32-point risk score for projecting the individualized absolute cumulative risk of liver cancer based on the six widely accessible and easily measured variables: age, sex, alcohol consumption, BMI, psychological trauma, and liver diseases in mothers, presenting an excellent discriminative ability and calibration. The risk scores successfully categorized HBV carriers into the extreme-high-risk and low-risk groups with significant differences in liver cancer cumulative incidence. In addition, to our knowledge, this is the first study to develop a live cancer risk prediction model only on the basis of traditional epidemiological parameters in patients chronically infected with HBV, which could be used in the primary screening stage for liver cancer.

The risk score developed in our study can provide guidance on whether HBV carriers need to receive the second-stage screening. First, according to Global Hepatitis Report 2017, more than 90 million patients are chronically infected with HBV in China at present (23). Apparently, it will cause unnecessary resource waste if all chronic hepatitis $\mathrm{B}(\mathrm{CHB})$ patients underwent regular liver cancer screening, especially for low-risk individuals. Second, further examination including AFP and ultrasound may result in psychological burden, blooding, and anxiety. Upon these considerations, the application of the risk scores at the primary screening stage would be necessary, which could narrow down the coverage of high-risk individuals of liver cancer for priority of liver cancer screening in $\mathrm{CHB}$ patients significantly. The results showed that $\mathrm{CHB}$ patients with a score of less than 5 may not need vigorous liver cancer screenings or follow-up within 3 years, and $76.02 \%$ of $\mathrm{CHB}$ patients were found to be at extremely high risk of our study. In our study, we aimed to identify individuals who had extremely high risks of liver cancer. When the cutoff value was set at 5, sensitivity and specificity could be relatively optimal. At the same time, we could detect as many potential extreme-high-risk patients as possible. Additionally, the individualized absolute risk of liver cancer could also be estimated at different time points, so patients chronically infected with HBV can monitor their health status by themselves. However, we have to note that external validation is warranted before applying our risk prediction model due to the diverse characteristics of the population in different regions.

Several variables are well-established risk factors associated with the development of liver cancer that have not been included in the final model. Smoking could increase the risk of liver cancer, which was statistically significant in the univariate analysis of our study; however, no significant association was observed in the multivariate analysis. Long-time follow-up is needed in the future to check the contribution of smoking to liver cancer development. Given the significant difference in the smoking rate and susceptibility of smoking between males and females, similar to the alcohol consumption (24), it is unreasonable to apply the same cutoff points to classify smoking intensity for men and women. In addition, to strengthen our results, we also classified smoking intensity for males and females with the application of the same criteria and achieved the identical conclusion. Cirrhosis as a strong risk factor of liver cancer refers to a disease in which liver cells become damaged and are replaced by scar tissue (25), irreversible in its advanced stage. To diagnose cirrhosis, you need to provide medical history, a physical exam, and a series of tests such as blood, imaging test, and liver biopsy (26). However, a standardized definition of cirrhosis has not yet been reached well so far, and thus, the diagnosis of cirrhosis is subjective to some extent. In our study, to make it user-friendly and navigate

TABLE 4 | Application of the risk prediction model or the risk score to specific individual.

\begin{tabular}{|c|c|c|c|c|c|}
\hline Risk factors & Case 1 & Case 2 & Case 3 & Case 4 & Case 5 \\
\hline Sex & M & M & $\mathrm{F}$ & M & $\mathrm{F}$ \\
\hline Psychological trauma & $N$ & Y & Y & Y & Y \\
\hline Liver diseases in mothers & $\mathrm{N}$ & Y & $\mathrm{Y}$ & $\mathrm{N}$ & $\mathrm{N}$ \\
\hline Alcohol consumption (g/week ethanol) & 600 & 700 & 0 & 0 & 0 \\
\hline $\mathrm{f}, \mathrm{M}$ & -0.058 & 1.99 & 0.268 & -0.331 & -1.21 \\
\hline
\end{tabular}

M, Male; F, Female; N, No; Y, Yes. 


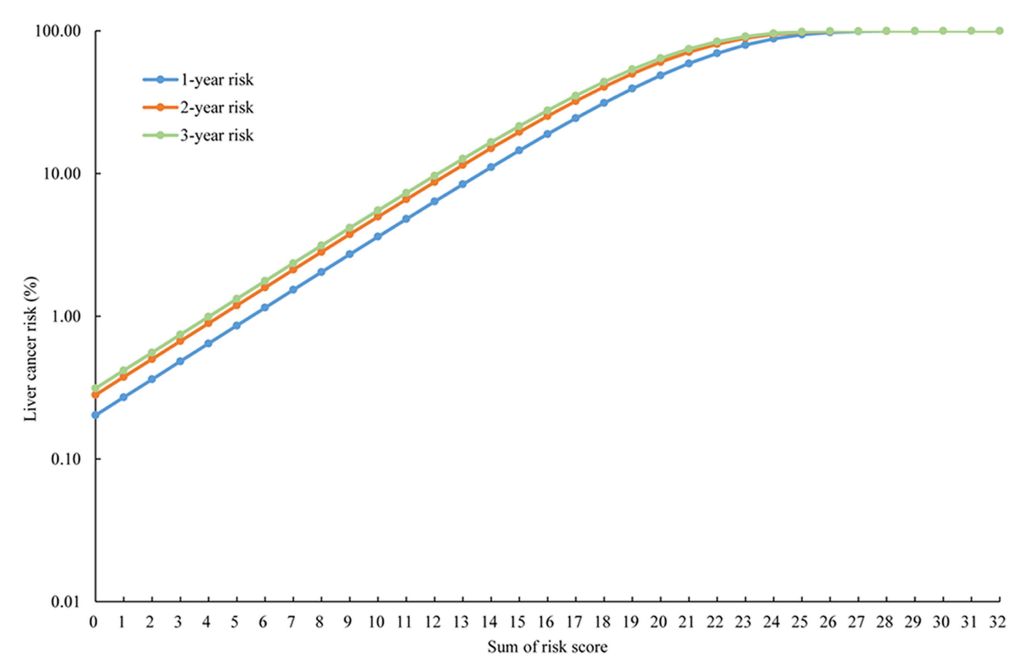

FIGURE 2 | The cumulative risk of developing liver cancer of risk score at 1 year, 2 years, and 3 years.

the prediction model for people accurately, we therefore did not incorporate cirrhosis into the final risk prediction model. Obesity is thought to be an independent risk factor of developing liver cancer (27). Michikawa et al. (28) devised a risk score containing age, sex, alcohol consumption, body mass index, diabetes, coffee consumption, and hepatitis $\mathrm{B}$ and $\mathrm{C}$ virus infection from 17,654 Japanese participants, including approximately $434 \mathrm{CHB}$ patients and 970 patients with HCV infection. Individuals with $\mathrm{BMI} \geq 25$ had a higher risk of liver cancer, compared with people with low BMI. However, an opposite result in our study was found, which might be associated with the different population characteristics. Participants in the present study are all chronically infected with HBV for a long time, presenting a poor health status and limited liver function.

A number of risk prediction models have been developed to identify high-risk individuals of liver cancer development in HBV carriers. Yang et al. (29) developed a 17-point risk score estimating the risk of developing liver cancer at 3, 5, and 10 years on the basis of age, sex, serum alanine aminotransferase concentrations, HBV DNA levels, and HBeAg serostatus. Wong et al. (30) derived a nomogram from a cohort of 1,005 CHB patients consisting of age, albumin, bilirubin, HBV DNA, and cirrhosis. Both studies presented a satisfactory accuracy in predicting the probability of liver cancer in patients with HBV infection, but their main objective was to provide an accurate instrument in diagnosing liver cancer in clinical environment. The two risk scores may not be adaptable as a primary screening method. Noteworthy, many risk scores put too much emphasis on viral factors, limiting their widespread application. Fan et al. (31) generated aMAP score without regard to any hepatitis virus in a cohort of patients chronically infected with HBV using 4 non-viral variables, which are age, male sex, albumin-bilirubin score, and platelets counts, respectively. Although the high discriminatory performance allowed a further improvement in the detection of liver cancer, the formula for the aMAP score is relatively complex.

TABLE 5 | The accuracy of the risk score for liver cancer.

\begin{tabular}{|c|c|c|c|c|c|}
\hline \multirow{2}{*}{ Risk scores } & \multirow[t]{2}{*}{ High-risk individuals (\%) } & \multicolumn{4}{|c|}{ Indices } \\
\hline & & Liver cancer $(N)$ & Sensitivity (\%) & Specificity (\%) & Youden index (\%) \\
\hline 0 & $10,536(100.00)$ & 203 & 100.00 & 0.00 & 0.00 \\
\hline 1 & 10,490 (99.56) & 203 & 100.00 & 0.45 & 0.45 \\
\hline 2 & 10,287 (97.64) & 202 & 99.51 & 2.40 & 1.91 \\
\hline 3 & 9,882 (93.79) & 201 & 99.01 & 6.31 & 5.32 \\
\hline 4 & 9,092 (86.29) & 198 & 97.54 & 13.93 & 11.47 \\
\hline 5 & 8,009 (76.02) & 189 & 93.10 & 24.32 & 17.42 \\
\hline 6 & 6,632 (62.95) & 167 & 82.27 & 37.43 & 19.70 \\
\hline 7 & $4,897(46.48)$ & 148 & 72.91 & 54.04 & 26.95 \\
\hline 8 & 3,428 (32.54) & 119 & 58.62 & 67.98 & 26.60 \\
\hline 9 & $2,239(21.25)$ & 94 & 46.31 & 79.24 & 25.55 \\
\hline 10 & $1,151(10.92)$ & 69 & 33.99 & 89.53 & 23.52 \\
\hline 11 & 491 (4.66) & 334 & 16.75 & 95.58 & 12.33 \\
\hline 12 & $220(2.09)$ & 19 & 9.36 & 98.05 & 7.41 \\
\hline 13 & $45(0.43)$ & 3 & 1.48 & 99.59 & 1.07 \\
\hline
\end{tabular}




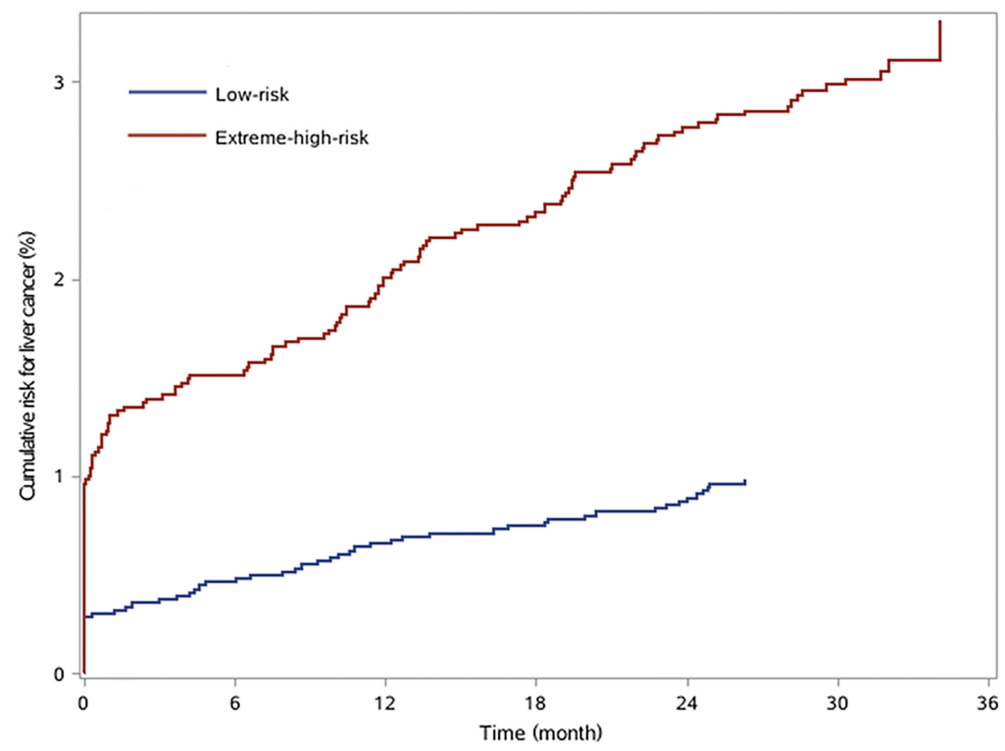

FIGURE 3 | The cumulative risk for liver cancer in chronic hepatitis B patients with low risk and extreme high risk.

A

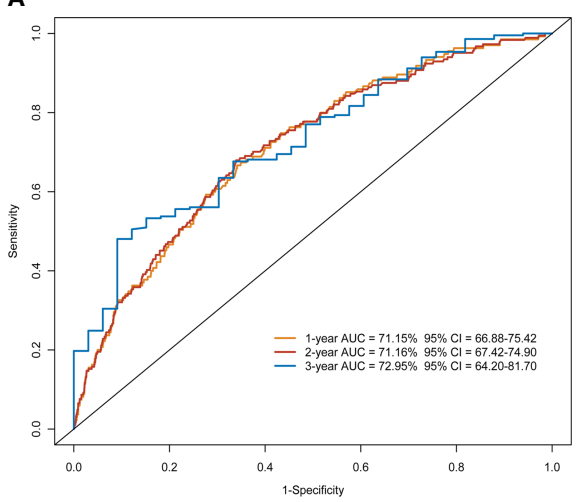

B

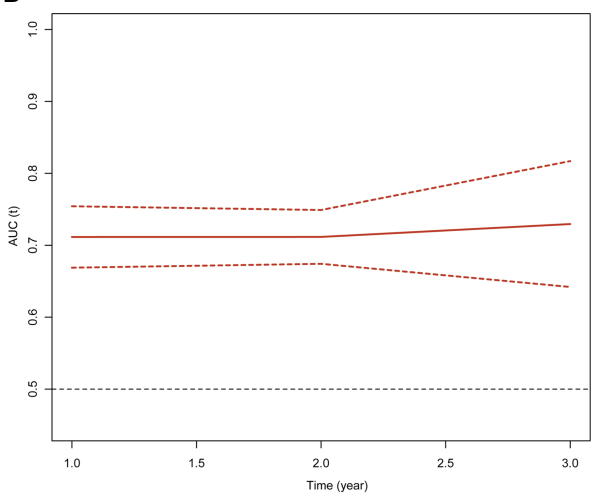

FIGURE 4 | Time-dependent ROC curve and AUC analyses of prediction for developing liver cancer. (A) ROC and (B) AUC.

Our study has some notable strengths. First, the dataset used in this study was from a large cohort of patients chronically infected with hepatitis B in seven sites, avoiding selection bias effectively. We adopted the same criterion to identify liver cancer for each site and each person. All liver cancer cases diagnosed at baseline were identified further through CT or MRI. Cases collected at the follow-up stage were matched through high-quality cancer registries and death surveillance system. Furthermore, most cases were found through active follow-up such as a home visit or telephone communication. Second, the risk prediction model could quantify the 3-year absolute risk of liver cancer in $\mathrm{CHB}$ patients without any laboratory tests, suggesting information for epidemiological workers or clinicians to determine who should or should not need to receive further examination regarding their individual annual risk of developing liver cancer. However, we still have to acknowledge several limitations. External validation has not yet been carried out, limiting the generalizability of the risk prediction model to a certain extent. In addition, we did not consider the role of $\mathrm{HCV}$ to liver cancer development. It is necessary to incorporate the HCV status in the development of the risk prediction model in the future studies in view of the etiology of liver cancer in China, which will be beneficial to calculate the risk of liver cancer.

\section{CONCLUSIONS}

A simple-to-use risk prediction model of age, sex, alcohol consumption, BMI, psychological trauma, and liver diseases in mothers was developed and internally validated, which could 


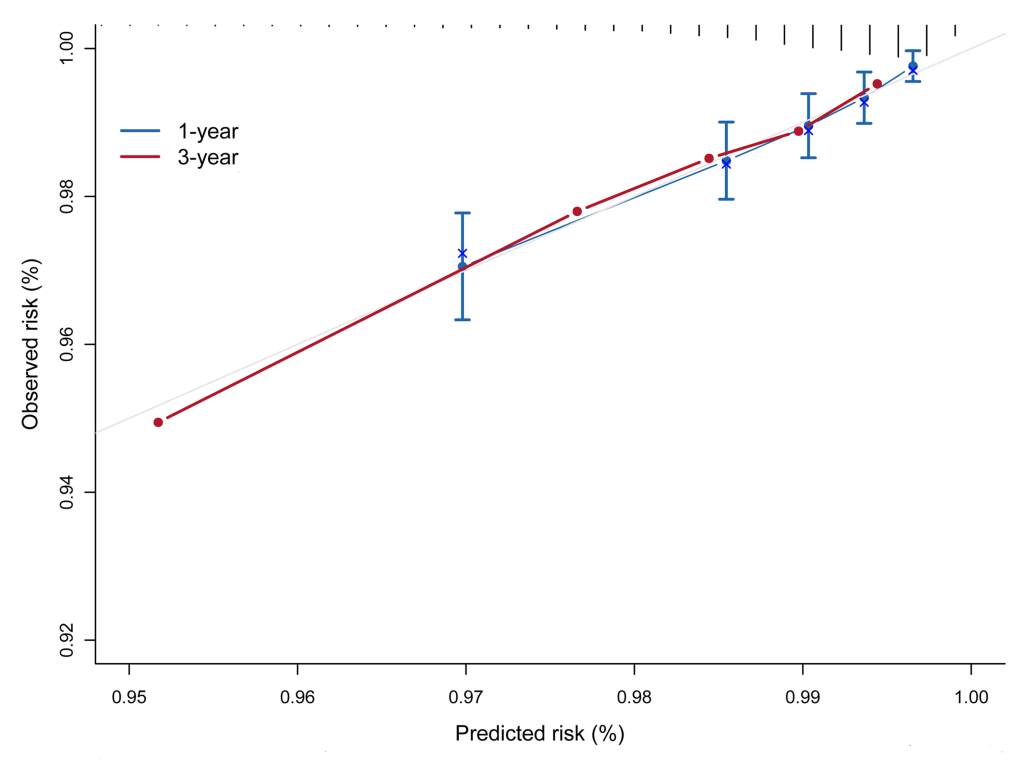

FIGURE 5 | Calibration curve of the prediction model.

quantify the 3-year absolute risk of liver cancer in patients with HBV. Extreme-high-risk individuals could be identified effectively by the new scoring system. This risk prediction model could be used as a primary screening method for liver cancer.

\section{DATA AVAILABILITY STATEMENT}

The raw data supporting the conclusions of this article will be made available by the authors, without undue reservation.

\section{ETHICS STATEMENT}

This study was approved by the Ethics Review Committee of the Cancer Hospital, Chinese Academy and Medical Sciences. The patients/participants provided their written informed consent to participate in this study. Written informed consent was obtained from the individual(s) for the publication of any potentially identifiable images or data included in this article.

\section{REFERENCES}

1. World Health Organization. Global Health Sector Strategy on Viral Hepatitis 2016-2021. Switzerland: WHO Press (2016).

2. Stanaway JD, Flaxman AD, Naghavi M, Fitzmaurice C, Vos T, Abubakar I, et al. The Global Burden of Viral Hepatitis From 1990 to 2013: Findings From the Global Burden of Disease Study 2013. Lancet (Lond Engl) (2016) 388 (10049):1081-8. doi: 10.1016/S0140-6736(16)30579-7

\section{AUTHOR CONTRIBUTIONS}

Conceptualization: WC and MC. Investigation: CX, HL, DS, SH, and LL. Supervision: JP. Writing-Original Draft: MC. All authors contributed to the article and approved the submitted version.

\section{FUNDING}

This study was supported by the National Natural Science Foundation of China (No. 81974492), the Sanming Project of Medicine in Shenzhen (No. SZSM201911015), and the Nonprofit Central Research Institute Fund of Chinese Academy of Medical Sciences (No. 2019PT320027).

\section{ACKNOWLEDGMENTS}

We gratefully acknowledge all workers involved populationbased cancer screening center in providing cancer records, data collection, auditing, verification, and database management.

3. Zhang BH, Yang BH, Tang ZY. Randomized Controlled Trial of Screening for Hepatocellular Carcinoma. J Cancer Res Clin Oncol (2004) 130(7):417-22. doi: 10.1007/s00432-004-0552-0

4. Kemp W, Pianko S, Nguyen S, Bailey MJ, Roberts SK. Survival in Hepatocellular Carcinoma: Impact of Screening and Etiology of Liver Disease. J Gastroenterol Hepatol (2005) 20(6):873-81. doi: 10.1111/j.1440-1746.2005.03844.x

5. Izzo F, Piccirillo M, Albino V, Palaia R, Belli A, Granata V, et al. Prospective Screening Increases the Detection of Potentially Curable Hepatocellular 
Carcinoma: Results in 8,900 High-Risk Patients. HPB (Oxford) (2013) 15 (12):985-90. doi: 10.1111/hpb.12080

6. Cao M, Li H, Sun D, He S, Yu Y, Li J, et al. Cancer Screening in China: The Current Status, Challenges, and Suggestions. Cancer Lett (2021) 506:120-7. doi: 10.1016/j.canlet.2021.02.017

7. Woldegiorgis AE, Erku W, Medhin G, Berhe N, Legesse M. CommunityBased Sero-Prevalence of Hepatitis B and C Infections in South Omo Zone, Southern Ethiopia. PloS One (2019) 14(12):e0226890-e. doi: 10.1371/ journal.pone. 0226890

8. The Ministry of Health Disease Control Burean ECoEDaToC. Technological Program on Cancer Early Detection and Treatment (Version 2011). Beijing: People's Medical Publishing House (2011).

9. Professional Committee for Prevention and Control of Hepatobiliary and Pancreatic Diseases of Chinese Preventive Medicine Association, Professional Committee for Hepatology, Chinese Research Hospital Association, Chinese Society of Hepatology, Chinese Medical Association and Prevention of Infection Related Cancer Group,Specialist Committee of Cancer Prevention and Control of Chinese Preventive Medicine Association. Guideline for Stratified Screening and Surveillance of Primary Liver Cancer (2020 Edition). Chin J Hepatobiliary Surg (2021) 27(1):12-29. doi: 10.3760/ cma.j.cn113884-20201127-00602

10. Fan C, Li M, Gan Y, Chen T, Sun Y, Lu J, et al. A Simple AGED Score for Risk Classification of Primary Liver Cancer: Development and Validation With Long-Term Prospective HBsAg-Positive Cohorts in Qidong, China. Gut (2019) 68(5):948. doi: 10.1136/gutjnl-2018-316525

11. Yuen MF, Tanaka Y, Fong DY, Fung J, Wong DK, Yuen JC, et al. Independent Risk Factors and Predictive Score for the Development of Hepatocellular Carcinoma in Chronic Hepatitis B. J Hepatol (2009) 50(1):80-8. doi: 10.1016/ j.jhep.2008.07.023

12. Aoki $\mathrm{T}$, Iijima $\mathrm{H}$, Tada $\mathrm{T}$, Kumada $\mathrm{T}$, Nishimura $\mathrm{T}$, Nakano $\mathrm{C}$, et al. Prediction of Development of Hepatocellular Carcinoma Using a New Scoring System Involving Virtual Touch Quantification in Patients With Chronic Liver Diseases. J Gastroenterol (2017) 52(1):104-12. doi: 10.1007/ s00535-016-1228-7

13. Chung JW, Jang ES, Kim J, Jeong SH, Kim N, Lee DH, et al. Development of a Nomogram for Screening of Hepatitis B Virus-Associated Hepatocellular Carcinoma. Oncotarget (2017) 8(63):106499-510. doi: 10.18632/ oncotarget.22498

14. Qu C, Wang Y, Wang P, Chen K, Wang M, Zeng H, et al. Detection of EarlyStage Hepatocellular Carcinoma in Asymptomatic HBsAg-Seropositive Individuals by Liquid Biopsy. Proc Natl Acad Sci USA (2019) 116(13):630812. doi: $10.1073 /$ pnas. 1819799116

15. Chen J, Zhu J, Wang G, Groopman JD, Kensler TW. Qidong: A Crucible for Studies on Liver Cancer Etiology and Prevention. Cancer Biol Med (2019) 16 (1):24-37. doi: 10.20892/j.issn.2095-3941.2018.0394

16. El-Serag HB, Rudolph KL. Hepatocellular Carcinoma: Epidemiology and Molecular Carcinogenesis. Gastroenterology (2007) 132(7):2557-76. doi: 10.1053/j.gastro.2007.04.061

17. Otani T, Iwasaki M, Yamamoto $\mathrm{S}$, Sobue $\mathrm{T}$, Hanaoka $\mathrm{T}$, Inoue $\mathrm{M}$, et al. Alcohol Consumption, Smoking, and Subsequent Risk of Colorectal Cancer in Middle-Aged and Elderly Japanese Men and Women: Japan Public Health Center-Based Prospective Study. Cancer Epidemiol Biomarkers Prev (2003) 12 (12):1492-500.

18. Li X, Yu C, Guo Y, Bian Z, Shen Z, Yang L, et al. Association Between Tea Consumption and Risk of Cancer: A Prospective Cohort Study of 0.5 Million Chinese Adults. Eur J Epidemiol (2019) 34(8):753-63. doi: 10.1007/s10654019-00530-5

19. Ugai T, Matsuo K, Sawada N, Iwasaki M, Yamaji T, Shimazu T, et al. Smoking and Subsequent Risk of Leukemia in Japan: The Japan Public Health Center-
Based Prospective Study. J Epidemiol (2017) 27(7):305-10. doi: 10.1016/ j.je.2016.07.005

20. Weir CB, Jan A. BMI Classification Percentile And Cut Off Points. StatPearls. Treasure Island (FL: StatPearls Publishing Copyright () 2021, StatPearls Publishing LLC (2021).

21. Sullivan LM, Massaro JM, D'Agostino RBSR. Presentation of Multivariate Data for Clinical Use: The Framingham Study Risk Score Functions. Stat Med (2004) 23(10):1631-60. doi: 10.1002/sim.1742

22. Wen CP, Lin J, Yang YC, Tsai MK, Tsao CK, Etzel C, et al. Hepatocellular Carcinoma Risk Prediction Model for the General Population: The Predictive Power of Transaminases. J Natl Cancer Inst (2012) 104(20):1599-611. doi: $10.1093 /$ jnci/djs372

23. World Health Organization. Global Hepatitis Report (2017). Available at: https://www.who.int/publications/i/item/global-hepatitis-report-2017.

24. Trichopoulos D, Bamia C, Lagiou P, Fedirko V, Trepo E, Jenab M, et al. Hepatocellular Carcinoma Risk Factors and Disease Burden in a European Cohort: A Nested Case-Control Study. J Natl Cancer Inst (2011) 103 (22):1686-95. doi: 10.1093/jnci/djr395

25. American Cancer Society. Liver Cancer Causes, Risk Factors, and Prevention . Available at: https://www.cancer.org/content/dam/CRC/PDF/Public/8699.00. pdf.

26. National Insititue of Diabetes and Digestive and Kidney Diseases. How Do Doctors Diagnose Cirrhosis? Available at: https://www.niddk.nih.gov/healthinformation/liver-disease/cirrhosis/diagnosis.

27. Saitta C, Pollicino T, Raimondo G. Obesity and Liver Cancer. Ann Hepatol (2019) 18(6):810-5. doi: 10.1016/j.aohep.2019.07.004

28. Michikawa T, Inoue M, Sawada N, Iwasaki M, Tanaka $\mathrm{Y}$, Shimazu $\mathrm{T}$, et al. Development of a Prediction Model for 10-Year Risk of Hepatocellular Carcinoma in Middle-Aged Japanese: The Japan Public Health CenterBased Prospective Study Cohort II. Prev Med (2012) 55(2):137-43. doi: 10.1016/j.ypmed.2012.05.017

29. Yang HI, Yuen MF, Chan HL, Han KH, Chen PJ, Kim DY, et al. Risk Estimation for Hepatocellular Carcinoma in Chronic Hepatitis B (REACH-B): Development and Validation of a Predictive Score. Lancet Oncol (2011) 12 (6):568-74. doi: 10.1016/s1470-2045(11)70077-8

30. Wong VW, Chan SL, Mo F, Chan TC, Loong HH, Wong GL, et al. Clinical Scoring System to Predict Hepatocellular Carcinoma in Chronic Hepatitis B Carriers. J Clin Oncol (2010) 28(10):1660-5. doi: 10.1200/jco.2009.26.2675

31. Fan R, Papatheodoridis G, Sun J, Innes H, Toyoda H, Xie Q, et al. aMAP Risk Score Predicts Hepatocellular Carcinoma Development in Patients With Chronic Hepatitis. J Hepatol (2020) 73(6):1368-78. doi: 10.1016/ j.jhep.2020.07.025

Conflict of Interest: The authors declare that the research was conducted in the absence of any commercial or financial relationships that could be construed as a potential conflict of interest.

Publisher's Note: All claims expressed in this article are solely those of the authors and do not necessarily represent those of their affiliated organizations, or those of the publisher, the editors and the reviewers. Any product that may be evaluated in this article, or claim that may be made by its manufacturer, is not guaranteed or endorsed by the publisher.

Copyright (c) $2022 \mathrm{Cao}, \mathrm{Li}$, Sun, He, Xia, Lei, Peng and Chen. This is an open-access article distributed under the terms of the Creative Commons Attribution License (CC BY). The use, distribution or reproduction in other forums is permitted, provided the original author(s) and the copyright owner(s) are credited and that the original publication in this journal is cited, in accordance with accepted academic practice. No use, distribution or reproduction is permitted which does not comply with these terms. 